\title{
Advanced Spaceborne Thermal Emission and Reflection Radiometer (ASTER) Overview
}

The National Aeronautics and Space Administration (NASA) launched Terra, the Earth Observing System's (EOS) flagship satellite platform on December 18, 1999. The polarorbiting Terra contains five remote sensing instruments, which enable the scientific study and analyses of global terrestrial processes and manifestations of global change. One of the five instruments is the multispectral Advanced Spaceborne Thermal Emission and Reflection Radiometer (ASTER), which is built in Japan by a consortium of government, industry, and research groups. It has three spectral bands in the visible near-infrared region (VNIR), six bands in the shortwave infrared region (SWIR), and five bands in the thermal infrared region (TIR), with 15-, 30-, and 90-meter ground resolutions, respectively. This combination of wide spectral coverage and high spatial resolution allows ASTER to discriminate among a wide variety of surface materials. The VNIR subsystem also has a backwardviewing telescope for high-resolution (15-meter) stereoscopic observation in the along-track direction, which facilitates the generation of digital elevation models (DEM).

The ASTER instrument is unique in two respects: it provides the highest spatial resolution surface spectral reflectance, temperature, and emissivity data of all the Terra sensors, and it is capable of being scheduled to fulfill on-demand data acquisition requests. The ASTER data products include surface reflectance, surface radiance, surface kinetic temperature, surface emissivity, brightness temperature at sensor, DEM, and orthorectified data. ASTER data contribute to a wide array of application areas, including geology and soils, vegetation and ecosystem dynamics, carbon cycling, hazards monitoring (volcanoes, wildfires, floods, landslides, and coastal erosion), land surface climatology, hydrology, and glaciology.

The ASTER Level-1B product is the staple input used to produce all on-demand geophysical products except the ASTER DEM. It offers the same number of bands at the same resolution as the Level-1 A product and is created by applying the radiometric-calibration and geometric-correction coefficients to the Level-1A data. The Land Processes Distributed Active Archive Center (LP DAAC) archives and maintains ASTER Level-1A data received from the Ground Data System (GDS) in Japan. All higher-level ASTER data products are produced on-demand

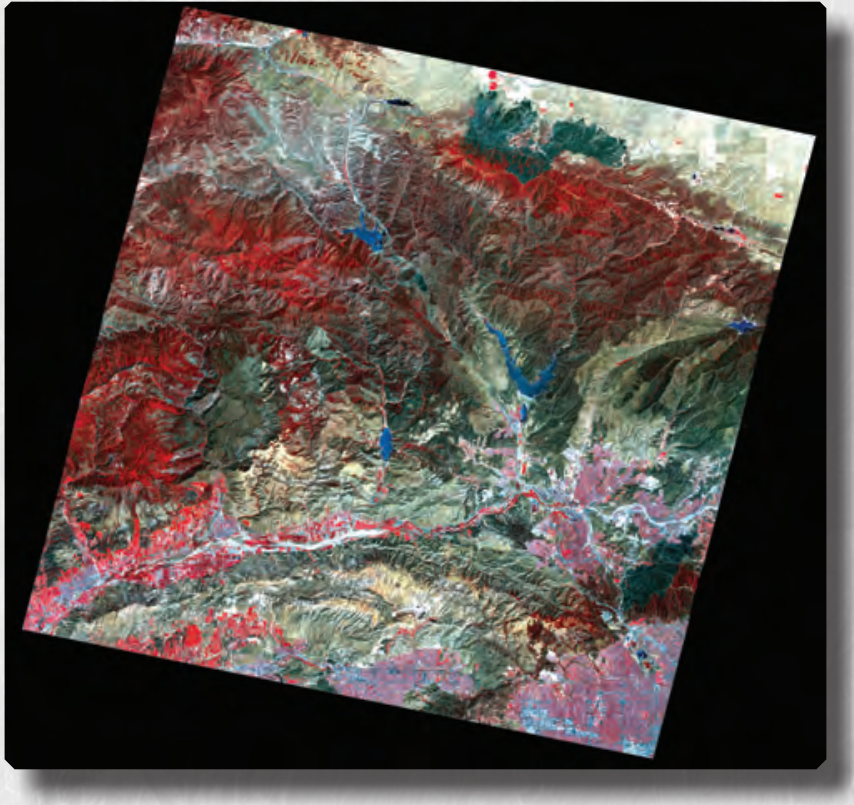

This is an ASTER orthorectified visible near-infrared image, which shows the northwestern part of Los Angeles County with a backdrop of the Tehachapi Mountains. The scene center coordinates are $34.5^{\circ} \mathrm{N}$. latitude and $118.7^{\circ} \mathrm{W}$. longitude. In the lower right is the northwestern end of the San Fernando Valley and Santa Clarita to its north. In the middle right is the V-shaped Castaic Lake and Interstate 5, which trends northwest-southeast. Healthy vegetation appears in red in contrast to a couple of burn scars (indicated by the darkened areas): one in the middle left (north of Simi Valley), the other in the north in the Angeles National Forest.

at the LP DAAC. A similar suite of products is produced at the GDS facility in Tokyo, Japan.

ASTER data and products are registered to the Universal Transverse Mercator (UTM) map projection and coordinate system. The majority of the data and products are provided in a specific implementation of the Hierarchical Data Format called HDF-EOS. For more details on ASTER data and its product suite, please visit https://lpdaac.usgs.gov/lpdaac/products/ aster_products_table. 


\section{Data Set Characteristics:}

Area:

Approximately 60 x 60 kilometers

Acquisition date and time:

$$
\text { 2004-08-07, 18:51:31 }
$$

Image dimensions:

VNIR: 4,200 rows x 4,980 columns

VNIR (3B): 4,600 rows x 4,980 columns

SWIR: 2,100 rows x 2,490 columns File size:

TIR: 700 rows x 830 columns

$\operatorname{VNIR}(1,2,3 \mathrm{~N})=62,748,000$ bytes

$\operatorname{VNIR}(3 \mathrm{~B})=22,908,000$ bytes
SWIR (4-9) $=31,374,000$ bytes

TIR $(10-14)=5,810,000$ bytes

Total $=118$ megabytes

Spatial resolution:

$$
\begin{aligned}
& \text { VNIR }=15 \text { meters } \\
& \text { SWIR }=30 \text { meters } \\
& \text { TIR }=90 \text { meters }
\end{aligned}
$$

Projection:

Universal Transverse Mercator (UTM)

\begin{tabular}{|c|c|c|c|}
\hline Short name & Long name & Level & $\begin{array}{c}\text { Spatial } \\
\text { resolution } \\
\text { (meters) }\end{array}$ \\
\hline \multicolumn{4}{|c|}{ ASTER Routine Products } \\
\hline AST_L1A & ASTER L1A Reconstructed Unprocessed Instrument Data & L1A & $15,30,90$ \\
\hline AST_L1AE & ASTER Expedited L1A Reconstructed Unprocessed Instrument Data & L1A & $15,30,90$ \\
\hline AST_L1BE & ASTER Expedited L1B Registered Radiance at the Sensor & L1B & $15,30,90$ \\
\hline \multicolumn{4}{|c|}{ ASTER On-Demand Products } \\
\hline AST_L1B & ASTER L1B Registered Radiance at the Sensor & L1B & $15,30,90$ \\
\hline AST_04 & ASTER On-Demand L2 Brightness Temperature at Sensor & L2 & 90 \\
\hline AST_05 & ASTER On-Demand L2 Surface Emissivity & L2 & 90 \\
\hline AST_07 & ASTER On-Demand L2 Surface Reflectance VNIR and SWIR & L2 & 15,30 \\
\hline AST_07XT & ASTER On-Demand L2 Surface Reflectance SWIR Crosstalk-Corrected & L2 & 15,30 \\
\hline AST_08 & ASTER On-Demand L2 Surface Kinetic Temperature & L2 & 90 \\
\hline AST_09 & ASTER On-Demand L2 Surface Radiance VNIR and SWIR & L2 & 15,30 \\
\hline AST_09XT & ASTER On-Demand L2 Surface Radiance SWIR Crosstalk-Corrected & L2 & 15,30 \\
\hline AST_09T & ASTER On-Demand L2 Surface Radiance TIR & L2 & 90 \\
\hline AST14DEM & ASTER On-Demand L3 Digital Elevation Model & L3 & 30 \\
\hline AST140TH & ASTER On-Demand L3 Orthorectified Images & L3 & $15,30,90$ \\
\hline AST14DMO & ASTER On-Demand L3 DEM (30 meter) and Orthorectified Images & L3 & $15,30,90$ \\
\hline
\end{tabular}

Data format:

HDF-EOS

The following table provides a list of all the ASTER Routine and On-Demand products available from the LP DAAC:

\section{Resources on ASTER:}

\section{LP DAAC URL:}

https://lpdaac.usgs.gov

Warehouse Inventory Search Tool URL:

https://wist.echo.nasa.gov/ wist/api/imswelcome/index.html Jet Propulsion Laboratory (JPL) ASTER URL:

http://asterweb.jpl.nasa.gov

LPDAAC-JPL ASTER User Handbook URL:

http://asterweb.jpl.nasa.gov/content/03_data/04_Documents/ aster_user_guide_v2.pdf

Ground Data System (GDS) in Japan URL:

http://www.gds.aster.ersdac.or.jp/gds_www2002/index_e.html

\section{Contact Information:}

LP DAAC User Services

U.S. Geological Survey

Earth Resources Observation and Science (EROS) Center 47914 252nd Street

Sioux Falls, SD, 57198-0001

Voice: 605-594-6116

Toll Free: 866-573-3222 (866-LPE-DAAC)

Fax: 605-594-6963

E-mail: LPDAAC@eos.nasa.gov

Web: https://LPDAAC.usgs.gov 